\title{
Morphological, histochemical and immunohistochemical studies of polar fox kidney
}

\author{
Maria Laszczyńska ${ }^{1}$, Małgorzata Ożgo ${ }^{2}$, Roman Szymeczko ${ }^{3}$, Marcin Wylot $^{4}$, \\ Sylwia Słuczanowska-Głąbowska ${ }^{5}$, Katarzyna Piotrowska ${ }^{5}$, Wiesław Skrzypczak ${ }^{2}$ \\ ${ }^{1}$ Laboratory of Histology and Developmental Biology, Pomeranian Medical University, \\ Szczecin, Poland \\ ${ }^{2}$ Department of Physiology, Cytobiology and Proteomics, Faculty of Biotechnology \\ and Animal Husbandry, West Pomeranian University of Technology, Szczecin, Poland \\ ${ }^{3}$ Department of Animal Physiology, Faculty of Animal Breeding and Biology, \\ University of Technology and Life Sciences, Bydgoszcz, Poland \\ ${ }^{4}$ Clinical Department of Anesthesiology and Intensive Care of Adult and Children, \\ Pomeranian Medical University, Szczecin, Poland \\ ${ }^{5}$ Department of Physiology, Pomeranian Medical University, Szczecin, Poland
}

\begin{abstract}
The aim of the present study was to evaluate the morphology and intermediate filaments cytokeratin, desmin and vimentin expression in the kidneys of the polar fox (Alopex lagopus). Routine morphological, histochemical and immunohistochemical techniques of examinations of the kidneys of adult male and female polar foxes were used. We found different localizations and different levels of immunoexpression of cytokeratin in epithelia of calyxes, distal tubules and Henle's loops, and also in endothelial cells. We also noted immunolocalization and immunoexpression of vimentin in mesangial cells, interstitial tissue and distal tubules. Desmin reactivity was revealed for muscle cells of arteries and mesangial cells. Our study is the first attempt to localize cytoskeletal intermediate filaments performed on polar fox kidneys. It is worth noting that our observations concerning the distribution of vimentin in the polar fox kidney may suggest that protein as being useful as a marker of distal tubules in the polar fox kidney. (Folia Histochemica et Cytobiologica 2012, Vol. 50, No. 1, 87-92)
\end{abstract}

Key words: polar fox, kidney, morphology, immunohistochemistry, cytokeratin, desmin, vimentin

\section{Introduction}

The polar fox (Alopex lagopus) is a medium weight canidae family member dwelling in extremely harsh environments. The recent focus of interest on this animal has regarded pollution accumulation in the organisms of arctic inhabitants; however, not much is yet known about its morphology and physiology. To

Correspondence address: M. Laszczyńska,

Laboratory of Histology and Developmental Biology,

Pomeranian Medical University,

Zolnierska Str. 48, 71-210 Szczecin, Poland; tel.: + 489148009 08, fax: + 48914800905 ;

e-mail: laszcz@pum.edu.pl survive in unfavorable conditions, the polar fox reveals numerous features including sophisticated water and electrolytes balance mechanisms described by Zhan et al. [1]. As in other mammals, in polar fox kidneys, the outer cortex and inner medulla can be distinguished. The whole organ is enveloped by a dense connective tissue capsule and consists of numerous tubular basic units - nephrons embedded within interstitial connective tissue. Each nephron begins in the cortex with renal corpuscle consisting of Bowman's capsule surrounding branched arterial glomerulus supported by mesenchyme origin mesangial cells. Enclosed within Bowman's capsule, the urinary space opens into a convoluted proximal tubule which passes into a straight proximal tubule entering 
the medulla, where it becomes Henle's loop. The Henle's loop penetrates toward the renal pelvis where it turns $180^{\circ}$ and comes back to the cortex as a straight distal tubule. In the cortex, a straight distal tubule coils into a distal convoluted tubule and opens into a collecting tubule of medullary rays which collect urine and finally drain into the renal pelvis [2-4].

The exceptional morphological features of polar fox kidneys compared to human have been listed by Hadziselimovic et al. [5]. The first are interlobar arteries passing through the renal calices in a loop composed of adipose tissue; the second is relatively the largest excretory apparatus, whose surface amounts to $31 \%$ of the whole kidney.

The main portion of the cytoskeleton is made up of microtubules and intermediate filaments. Intermediate filaments (IF) are a large family of proteins. Cytoplasmic IF proteins form flexible filaments with an approximate diameter of $10 \mathrm{~nm}$. In different stages of development, different kinds of IF proteins are expressed. Epithelia are characterized by cytokeratins, while vimentin is typical for cells of mesenchymal origin, and desmin is present mostly in muscle tissue. All three types of IF are present in the kidneys of adult mammals, but their expression and cell distribution varies and depends on the type of cell and species [6]. Zou et al. [7] showed changes in expression of IF proteins in rat kidneys after toxic injury. The main functions of IF in kidneys are sustaining cell shape, motility, cycle control and signal transduction $[6,8]$.

In the present study, we investigated polar fox kidneys' morphology and the immunoexpression of vimentin, desmin and cytokeratin. The polar fox demonstrates certain features enabling its survival in unfavorable conditions. We investigated immunolocalization of IF proteins to establish whether these cytoskeletal proteins have a different pattern of expression in the kidneys of the polar fox, due to specific living conditions.

\section{Material and methods}

Kidneys from ten male and ten female polar foxes were fixed, embedded in paraffin blocks and sliced into $4 \mu \mathrm{m}$ thick sections. For morphological and histochemical studies, hematoxylin-eosine (HE), PAS (in McManus and Hotchkiss modification) and Mallory in Trichrome modification staining, Bouin's fixative were used. For immunohistological studies, $4 \%$ paraformaldehyde fixative was used. Examinations were obtained using an Olympus BX40 light microscope combined with an Olympus Digital Camera (Olympus, Poland).

For immunohistochemical examinations of selected proteins, the EnVision + System HRP technique was used. As the first step, slides were deparaffinized and boiled in Tar- get Retrieval Solution (DAKO, Denmark) $\mathrm{pH}=6.0$ (for desmin and vimentin) and $\mathrm{pH}=9.0$ (for cytokeratin) to restore antigens. Subsequently, after endogenous peroxidase blocking with Peroxidase Blocking Reagent (DAKO, Denmark), primary antibodies were applied $[9,10]$. For cytokeratin expression, the cytokeratin clone MNF 116 monoclonal mouse anti-human antibody (DAKO, Denmark) was used, whereas for desmin, the desmin clone D33 monoclonal mouse anti-human antibody (DAKO, Denmark) was used, and for vimentin, the vimentin clone Vim 3B4 (DAKO, Denmark) monoclonal mouse anti-human antibody was used. After the recommended incubation time, primary antibodies were washed and secondary antibody: anti-mouse labeled polymer - horseradish peroxidase (HRP) was applied. Subsequently, after washing out the secondary antibody, AEC + + substrate chromogen was applied. As the last step, slides were counterstained with Mayer's hematoxylin and embedded with Faramount Aqueous Mounting Medium (DAKO, Denmark). Each step of the procedure was preceded by washing slides with PBS. As a negative control, we conducted reactions with primary antibodies replaced by goat serum.

The experimental protocol was approved by the Local Ethics Committee of Animals, nr 2/2010 (21.01.2010), Bydgoszcz, Poland.

\section{Results}

Our examinations revealed typical and untouched morphology of the kidney's cortex and medulla. Renal corpuscles, proximal and distal convoluted tubules were well distinguishable in the cortex (Figures 1A, C, E). Thin and thick arms of Henle's loops were well visible in the medulla (Figures 1B, D, F). There were no differences between genders of polar fox.

Immunohistochemical examinations revealed expression of all investigated cytoskeleton proteins: cytokeratin, desmin and vimentin (Tables 1-3). Very intense expression of cytokeratin was confirmed in transitional epithelium lining of renal calyxes. Strong or weak expression of cytokeratin was found in epithelium lining of distal tubules, Henle's loops, and strong expression in endothelial cells (Figures 2 A-D). Weak expression of cytokeratin was observed in collecting tubules, whereas epithelial cells of proximal tubules and glomerulus were negative (Table 1).

Immunoexpression of vimentin was present in cells of mesenchymal origin: strong reaction in intersitial tissue (asterix) and mesangial cells of gromeruli (arrow head). Very strong expression was marked in epithelial cells of distal tubules (arrows) (Figure $2 \mathrm{E}$ ) (Table 2).

Desmin expression was strong in smooth muscle cells of arcuate and intralobulares arteries and capillaries (Figure $2 \mathrm{~F}$ ); weak expression was observed in mesangial cells (Table 3). 

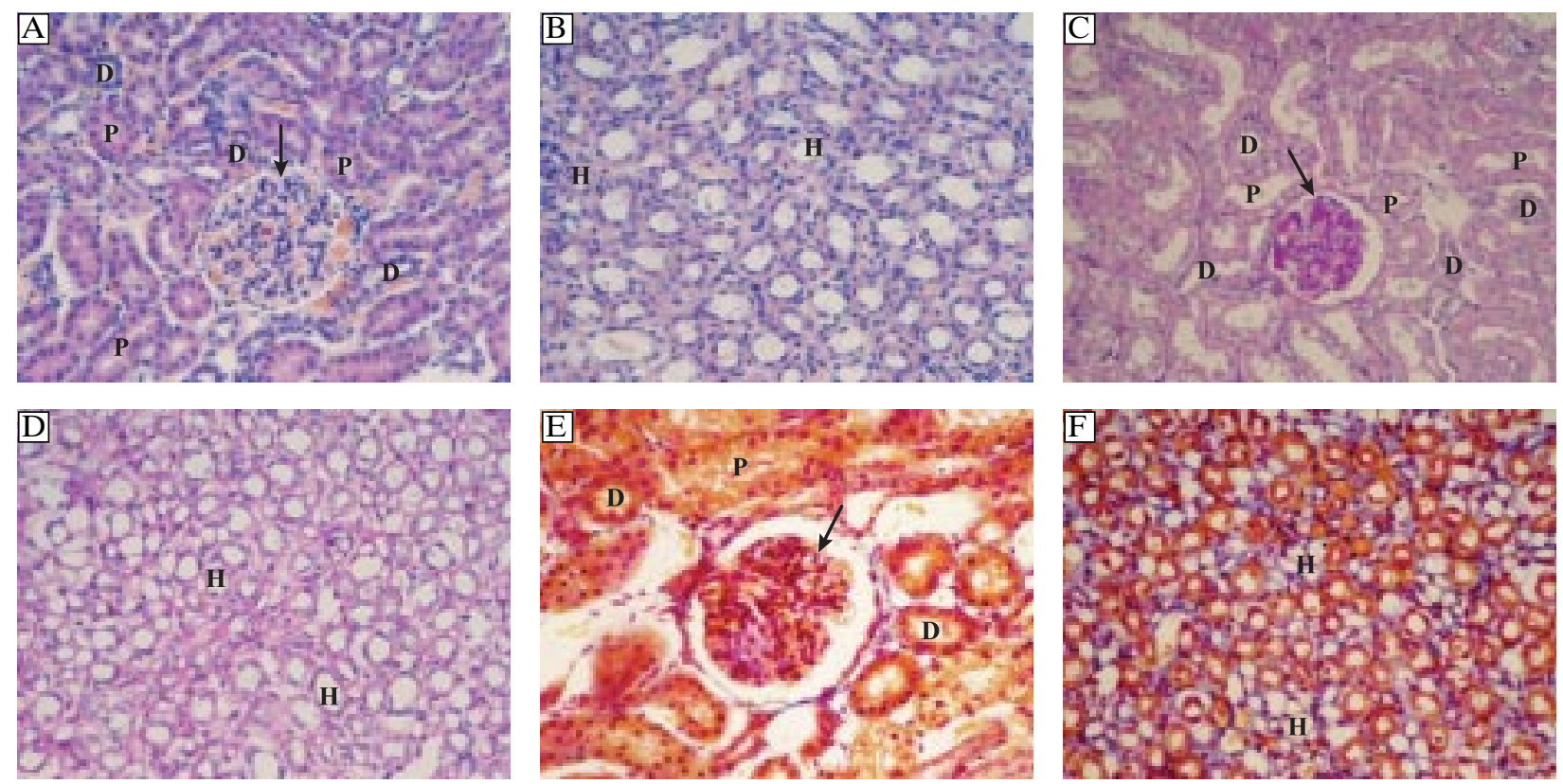

Figure 1. Morphology of polar fox kidney. A, B: H-E staining $(\times 400)$; C, D: PAS staining (× 400); E, F: Mallory with Trichrome modification $(\times 400)$. Glomeruli (arrow), proximal $(\mathrm{P})$ and distal $(\mathrm{D})$ convoluted tubules were visible in cortex (A, C, E). Henle's loops $(\mathrm{H})$ can be distinguished in medulla (B, D, F)
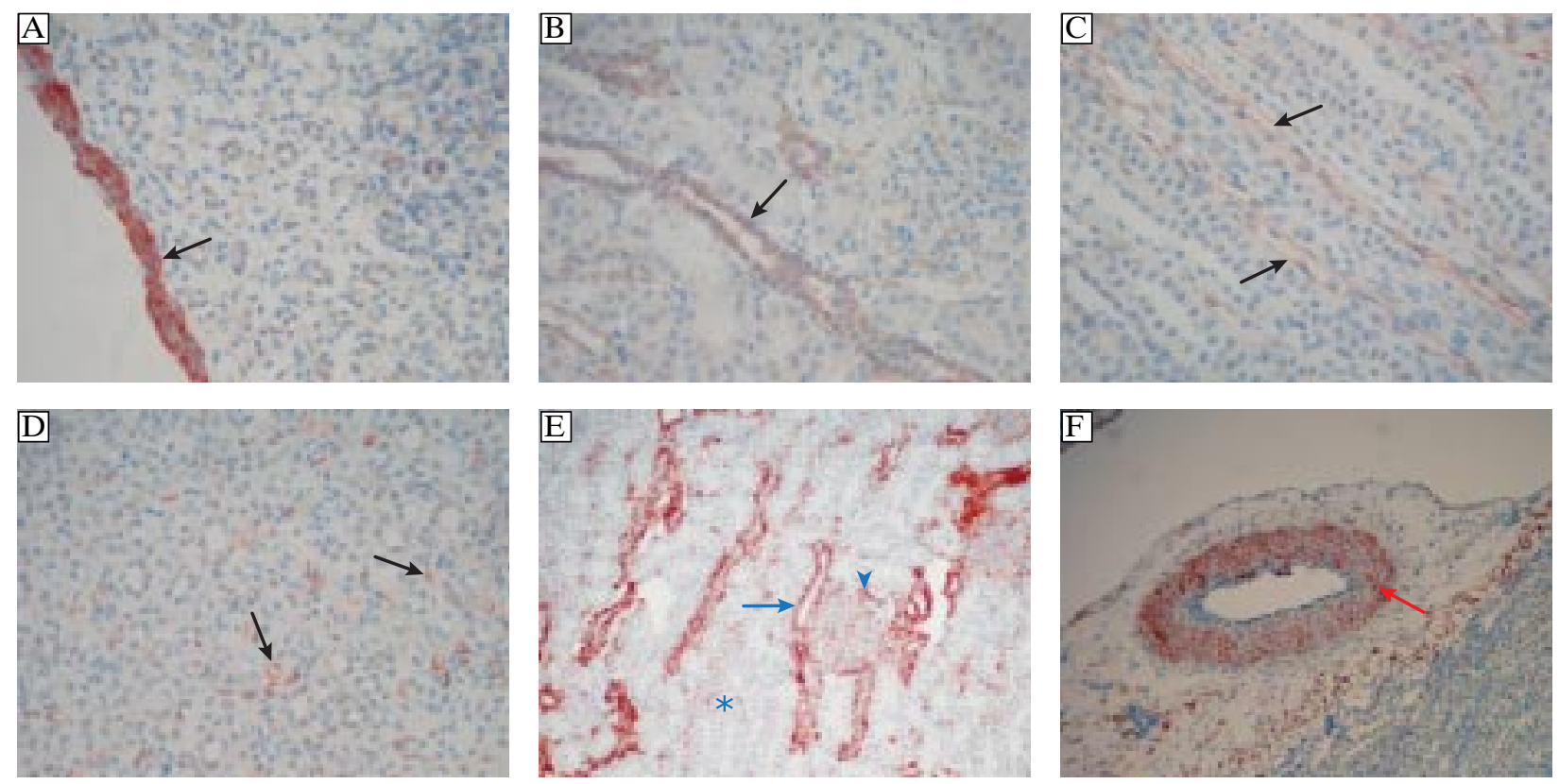

Figure 2. Immunolocalization and immunoexpression of cytokeratin $(\mathbf{A}-\mathbf{D})(\times 400)$, vimentin $(\mathbf{E})$ and desmin $(\mathbf{F})(\times 200)$ in different cells of female polar fox kidney. Very strong expression of cytokeratin (black arrow) in transitional epithelium of the calix (A); strong or weak expression of cytokeratin (black arrow) in cuboidal epithelium of distal convoluted tubule (B); strong or weak expression of cytokeratin (black arrow) in simple squamous epithelium of Henle's loops (C); strong expression of cytokeratin (black arrow) in endothelial cells (D). Very strong expression of vimentin in cuboidal epithelium of distal convoluted tubule (blue arrow), strong expression in mesangial cells (arrow head) and interstitial cells (blue asterix) (E). Strong expression of desmin (red arrow) in vascular smooth muscle cells (F) 
Table 1. Immunolocalization and immunoexpression of cytokeratin in different epithelial cells of polar fox kidney

\begin{tabular}{|l|c|c|c|c|c|c|}
\hline Gender & $\begin{array}{c}\text { Transitional } \\
\text { epithelium } \\
\text { of calyxes }\end{array}$ & $\begin{array}{c}\text { Cuboidal } \\
\text { epithelium } \\
\text { of proximal } \\
\text { tubules }\end{array}$ & $\begin{array}{c}\text { Cuboidal } \\
\text { epithelium } \\
\text { of distal tubules }\end{array}$ & $\begin{array}{c}\text { Squamous } \\
\text { epithelium } \\
\text { of Henle's loops }\end{array}$ & $\begin{array}{c}\text { Columnar or } \\
\text { cuboidal } \\
\text { epithelium } \\
\text { of the co } \\
\text { llecting ducts }\end{array}$ & $\begin{array}{c}\text { Endothelial } \\
\text { cells }\end{array}$ \\
\hline Male & +++ & - & $++/+$ & $++/+$ & + & ++ \\
\hline Female & +++ & - & $++/+$ & $++/+$ & + & ++ \\
\hline
\end{tabular}

+++ very strong; ++ strong; + weak; - negative

Table 2. Immunolocalization and immunoexpression of vimentin in different cells of polar fox kidney

\begin{tabular}{|l|c|c|c|c|c|}
\hline Gender & Interstitial cells & Mesangial cells & $\begin{array}{c}\text { Cuboidal epithelium } \\
\text { of proximal tubules }\end{array}$ & $\begin{array}{c}\text { Cuboidal epithelium } \\
\text { of distal tubules }\end{array}$ & $\begin{array}{c}\text { Columnar or cuboidal } \\
\text { epithelium of } \\
\text { the collecting ducts }\end{array}$ \\
\hline Male & ++ & ++ & - & +++ & - \\
\hline Female & ++ & ++ & - & +++ & - \\
\hline
\end{tabular}

+++ very strong; ++ strong; - negative

Table 3. Immunolocalization and immunoexpression of desmin in different cells of polar fox kidney

\begin{tabular}{|l|c|c|}
\hline Gender & $\begin{array}{c}\text { Vascular smooth } \\
\text { muscle cells }\end{array}$ & Mesangial cells \\
\hline Male & +++ & + \\
\hline Female & +++ & + \\
\hline
\end{tabular}

+++ very strong; + weak

\section{Discussion}

Our observations of the morphology and immunohistochemical localization of IF in polar fox kidneys correspond with similar observations made in humans and animals. The differences in results depend on the quality of antibodies used in experiments and also on the species and development stage of the kidney [7, 8, 11-14].

Morphological study of the polar fox kidney did not reveal any major difference compared to the described kidneys in mammalian species. We noted some differences in pattern of expression and localization of intermediate size filaments in various cells of polar fox kidneys.

Intermediate filaments have a very important function in the cells of kidneys. They are responsible for the functional organization and architecture of the cytoskeleton of cells. Cytokeratin sustains polarity and integrity of epithelia, vimentin establishes shape of cell, especially podocytes, while desmin is responsible for the contractility of cells. All types of IF are also responsible for motility, cell cycle control and signal transduction [11-13].
The expression level of cytoskeletal IF proteins can also be changed during pathologies. Zou et al. [7] revealed that in induced puromycin aminonucleoside nephrosis (PAN) in rats, which is a model of podocyte injury, the level of vimentin and desmin changed. In control rats, vimentin was expressed in podocytes and weakly in mesangial cells. Desmin immunoexpression was found in some mesangial cells and vascular smooth muscle cells. After the injury, transcripts for vimentin, and also desmin, were upregulated in different time points (day 3 for vimentin and day 10 for desmin). In our study, we observed distributions of vimentin and desmin in mesangial cells comparable to those observed by Zou et al. [7] in control rats.

Maruyama et al. [15] surprisingly revealed that desmin is a marker of proteinuria in the early stages of membranous nephropathy in elderly humans. They concluded that the expression of desmin in podocytes is upregulated in patients with idiopathic membranous nephropathy compared to other glomerular diseases including minimal-change nephrotic syndrome or minor glomerular abnormalities, or to the controls. Especially in elderly patients, desmin expression was associated with changes progression and heavy proteinuria, which may reflect phenotypic alteration of the podocyte. Similar upregulation of desmin was noted by Zou in PAN in rats [7].

Also, vimentin expression may change in the pathological process under fibrogenic stimuli inducing renal interstitial fibrosis. Yamate et al. [16] compared rat and canine fibrotic kidneys. In rats, both renal epithelial and interstitial cells showed positive reactions to vimentin, supporting the epithelial-mesenchymal transition theory; however, renal epitheli- 
um did not react to desmin, though interstitial cells were reactive. On the other hand, in dogs, renal epithelial reacted strongly to desmin, but interstitial cells did not; vimentin expression was infrequently seen in renal epithelial and interstitial cells of canine kidneys [16]. Unfortunately, the authors did not make a distinction between proximal and distal tubules, instead writing about "renal tubules". We also observed vimentin expression in interstitial cells and cells of the distal convoluted tubules in the polar fox which may be due to natural cognation between these species (family: Canidae).

Maretta et al. [17] detected vimentin in the podocytes, mesangial cells of the glomerulus, in the endothelium of renal capillaries, and stromal (interstitial) cells of sheep and goat kidneys.

Bravo et al. [18] noticed vimentin expression in the cortex in proximal tubules of rat kidneys after tubular injury with epithelial cell transdifferentiation. Lin et al. [19] and Hertig et al. [20] confirmed vimentin expression in regenerating tubules cells originating from renal tubular epithelial cells, the main source of renal repair. However, it was confirmed by Liu [21] that mature epithelial cells in adult kidneys may undergo mesenchymal transition in renal fibrogenesis with actin expression. On the other hand, other researchers have not confirmed changes of intermediate filament expression in pathological conditions.

Kaukinen et al. [22] noticed increased vimentin expression only in connective tissue scar in congenital nephrotic syndrome of Finnish type. Carev et al. [23] noticed that the coexpression of intermediate filament vimentin and cytokeratin in metanephric development is a temporary feature probably associated with mesenchymal to epithelial transformation of developing nephrons. In adult kidneys, such coexpression is associated with fibrosis or carcinomatous changes.

A large number of experiments with localization of IF in kidneys has been performed with human kidneys.

The oldest accessible data by Holthofer et al. [14] of human kidneys showed vimentin, but not cytokeratin, expression in undifferentiated cells of the metanephric mesenchyme, whereas in induced renal vesicles cells, only cytokeratin was expressed. In subsequent stages of development, the staining pattern changed. In fetal kidneys, the epithelial cells of proximal and distal tubules and of collecting ducts showed a cytoplasmic cytokeratin expression. In adult kidneys, positive reaction depended on the quality of antibody used. Vimentin was not found in tubular epithelial cells at any developmental stage, whereas the cells of collecting ducts showed a transient expression of vimentin in fetal kidneys. In adolescence, exceptional expression of only vimentin in the visceral epithelial cells of human glomeruli was noticed.

More recently, it has been noted that expression of intermediate size filaments can be useful in developing and adult human kidneys and in renal cell carcinoma [24]. These observations have resolved the controversy concerning intermediate-sized filament expression in the human kidney.

Ostalska-Nowicka et al. [25] revealed that in the control samples taken from normal renal cortex of human kidneys resected for localized neoplasm, the immunocytochemical expression of cytokeratine 18 was found only in epithelial cells of proximal and distal tubules. Vimentin was present in all podocytes, some mesangial cells, and the endothelium. However, these examinations also indicated that, in pathological conditions, reorganization of cytoskeletal proteins within immature podocytes may occur.

In the kidneys of the polar fox, we found different localization and different levels of cytokeratin immunoexpression in epithelia of calyxes, distal tubules, Henle's loops and also in endothelial cells. We also noted immunolocalization and immunoexpression of vimentin in mesangial cells, interstitial tissue and distal tubules. Desmin reactivity was revealed for muscle cells of arteries and mesangial cells.

These observations are in partial agreement with previous studies in mammals. In their multi-species study, Yaolta et al. [6] found vimentin in podocytes of humans, dogs, cattle and rats. Antivimentin antibody reacted also with some parietal cells, but not with tubular cells. The expression of cytokeratins was present in some podocytes in dogs and all human tubular cells. Anti-cytokeratin antibody also reacted with some portion of parietal cells of Bowman's capsule. Desmin was found only in rat podocytes.

These findings indicate that podocytes are characterized by intense vimentin staining in the higher vertebrates, and by desmin staining in the lower vertebrates.

Differences in the results of our study compared to that of Yaoita et al. [6] may be explained by the different antibodies used in the examinations of animal species. There are no specific antibodies against polar fox proteins, so we based ours on cross-reactivity of used antibodies. Yaoita et al. [8] also showed that expression of desmin varies between rat strains, and that immunoexpression of this protein increases with age.

Our immunohistological staining techniquesbased findings in the polar fox are convergent with the observations of Vilafranca et al. [26] who used ultrastructural, immunogold single and double label- 
ing techniques. In normal canine kidneys, the visceral glomerular epithelial cells (podocytes) expressed only vimentin, and cytokeratin was found exclusively in parietal glomerular epithelial cells. Aresu et al. [27] showed that in dogs' kidneys, epithelial tubular cells lose their cytokeratin staining characteristics and transdifferentiate into cells exhibiting a key mesenchymal feature of vimentin-positive staining in glomerulonephritis.

In conclusion, our study is the first attempt to localize cytoskeletal IFs performed on polar fox kidneys. We showed immunolocalization and expression of vimentin, cytokeratin and desmin in the cortex and medullary structures of polar fox kidneys. We believe that this experiment enlarges our knowledge about the cytoskeletal proteins in mammalian kidneys. It is worth noting that our observations concerning the distribution of vimentin in polar fox kidneys may suggest its utility as a marker of the kidney distal tubules of the polar fox.

\section{Acknowledgements}

This paper was supported by a grant from MNSW: NN311519340.

\section{References}

1. Zhan YM, Yasuda J, Too K. Reference data on the anatomy and serum biochemistry of the silver fox. Jpn J Vet Res. 1991;39:39-50.

2. Reilly Jr RF, Bulger RE, Kriz W. Structural-functional relationships in the kidney. In: Schrier RW, ed. Diseases of the kidney and urinary tract. Lippincot Williams \& Wilkins, Philadelphia 2007:2-53.

3. Sonne C, Wolkers H, Leifsson PS et al. Organochlorine-induced histopathology in kidney and liver tissue from Arctic fox (Vulpes lagopus). Chemosphere. 2008;7:1214-1224.

4. Heiene R, Eliassen KA, Risøen U, Neal LA, Cowgill LD. Glomerular filtration rate in dogs as estimated via plasma clearance of insulin and iohexol and use of limited-sample methods. Am J Vet Res. 2010;71:1100-1107.

5. Hadziselimovic H, Cus M. Blood vessels and excretory apparatus of the kidney in some wild animals. Acta Anat (Basel). 1975;91:71-82.

6. Yaoita E, Franke WW, Yamamoto T et al. Identification of renal podocytes in multiple species: higher vertebrates are vimentin positive/lower vertebrates are desmin positive. Histochem Cell Biol. 1999;111:107-115.

7. Zou J, Yaoita E, Watanabe Y et al. Upregulation of nestin, vimentin, and desmin in rat podocytes in response to injury. Virchows Arch. 2006;448:485-492.

8. Yaoita E, Kawasaki K, Yamamoto T et al. Variable expression of desmin in rat glomerular epithelial cells. Am J Pathol. 1990;136;899-908.

9. Gluhovschi C, Gluhovschi G, Potencz E et al. The endothelial cells markers von Willebrand Factor (vWF), CD31 and CD34 are lost in glomerulonephritis and no longer correlate with morphological indices of glomerular sclerosis, interstitial fibrosis, activity and chronicity. Folia Histochem Cytobiol. 2010;48:230-236.

10. Ostalska-Nowicka D, Nowicki M, Kondraciuk B et al. Expression of galetin-3 in nephrotic syndrome glomerulopathies in children. Folia Histochem Cytobiol. 2009;47:315-322.

11. Eckes B, Dogic D, Colucci-Guyon E et al. Impaired mechanical stability, migration and contractile capacity in vimentindeficient fibroblasts. J Cell Sci. 1998;111;1897-1907.

12. Magin TM, Vijayaraj P, Leube RE. Structural and regulatory functions of keratins. Exp Cell Res. 2007;313:2021-2032.

13. Oriolo AS, Wald FA, Ramsauer VP, Salas PJI. Intermediate filaments: a role in epithelial polarity. Exp Cell Res. 2007;313:2255-2264.

14. Holthofer H, Miettinen A, Lehto VP et al. Expression of vimentin and cytokeratin types of intermediate filament proteins in developing and adult human kidneys. Lab Invest. 1984;50:552-559.

15. Maruyama M, Sugiyama H, Sada K et al. Desmin as a marker of proteinuria in early stages of membranous nephropathy in elderly patients. Clin Nephrol. 2007;68:73-80.

16. Yamate J, Kuribayashi M, Kuwamura M et al. Differential immunoexpressions of cytoskeletons in renal epithelial and interstitial cells in rat and canine fibrotic kidneys, and in kidney-related cell lines under fibrogenic stimuli. Exp Toxicol Pathol. 2005;57:135-147.

17. Maretta M, Marettova E. Immunohistochemical demonstration of vimentin and S-100 protein in the kidneys. Gen Physiol Biophys. 1999;18:100-102.

18. Bravo J, Quirozy Y, Parra G et al. Vimentin and heat shock protein expression are induced in the kidney by angiotensin and by nitric oxide inhibition. Kidney Int Suppl. 2003;86:S46-S51.

19. Lin F, Moran A, Igarashi P. Intrarenal cells, not bone marrow-derived cells, are the major source for regeneration in postischemic kidney. J Clin Invest. 2005;115:1756-1764.

20. Hertig A, Verine J, Mougenot B et al. Risk factors for early epithelial to mesenchymal transition in renal grafts. $\mathrm{Am}$ J Transplant. 2006;6:2937-2946.

21. Liu Y. Epithelial to mesenchymal transition in renal fibrogenesis: pathologic significance, molecular mechanism, and therapeutic intervention. J Am Soc Nephrol. 2004;15:1-12.

22. Kaukinen A, Lautenschlager I, Helin $\mathrm{H}$ et al. Peritubular capillaries are rarefied in congenital nephrotic syndrome of the Finnish type. Kidney Int. 2009;75:1099-1108.

23. Carev D, Saraga M, Saraga-Babic M. Expression of intermediate filaments, EGF and TGF-alpha in early human kidney development. J Mol Histol. 2008;39:227-235.

24. Oosterwijk E, Van Muijen GN, Oosterwijk-Wakka JC et al. Expression of intermediate-sized filaments in developing and adult human kidney and in renal cell carcinoma.J Histochem Cytochem.1990;38:385-392.

25. Ostalska-Nowicka D, Zachwieja J, Nowicki M et al. Expression of intermediate filaments of podocytes within nephrotic syndrome glomerulopathies in children. Histochem Cell Biol. 2004;121:109-113.

26. Vilafranca M, Ferrer L, Wohlsein P et al. Ultrastructural colocalisation of vimentin and cytokeratin in visceral glomerular epithelial cells of dogs with glomerulonephritis. Res Vet Sci. 1995;59:87-91.

27. Aresu L, Rastaldi MP, Scanziani E et al. Epithelial-mesenchymal transition (EMT) of renal tubular cells in canine glomerulonephritis. Virchows Arch. 2007;451:937-942.

Submitted: 25 July, 2011

Accepted after reviews: 14 November, 2011 